\title{
Inadequate Instructions for Healthcare Professional
}

National Cancer Institute

\section{Source}

National Cancer Institute. Inadequate Instructions for Healthcare Professional. NCI

Thesaurus. Code C63087.

Problem associated with inaccuracies in any written, printed, or graphic matter that is affixed to the device or its packaging with any matter that accompanies the device including verbal instructions related to identification, technical description and use of the device provided by the device manufacturers that is intended for healthcare professionals. 